\title{
Quality Indicators for Small Bowel Capsule Endoscopy
}

\author{
Ki-Nam Shim ${ }^{1}$, Seong Ran Jeon², Hyun Joo Jang ${ }^{3}$, Jinsu Kim ${ }^{4}$, Yun Jeong Lim ${ }^{5}$, Kyeong Ok Kim ${ }^{6}$, Hyun Joo Song ${ }^{7}$, Hyun Seok Lee, \\ Jae Jun Park', Ji Hyun Kim ${ }^{10}$, Jaeyoung Chun ${ }^{11}$, Soo Jung Park ${ }^{9}$, Dong-Hoon Yang ${ }^{12}$, Yang Won Min ${ }^{13}$, Bora Keum ${ }^{14}$, Bo-In Lee ${ }^{4}$ and \\ Korean Gut Image Study Group
}

Department of Internal Medicine, ${ }^{1}$ Ewha Womans University School of Medicine, Seoul, ${ }^{2}$ Soonchunhyang University College of Medicine, Seoul, ${ }^{3}$ Hallym University College of Medicine, Hwaseong, ${ }^{4}$ The Catholic University of Korea, Seoul, ${ }^{5}$ Dongguk University College of Medicine, Goyang, ${ }^{6}$ Yeungnam University College of Medicine, Daegu, ${ }^{7}$ Jeju National University School of Medicine, Jeju, ${ }^{8}$ Kyungpook National University School of Medicine, Daegu, ${ }^{9}$ Yonsei University College of Medicine, Seoul, ${ }^{10}$ Inje University College of Medicine, Busan, ${ }^{11}$ Seoul National University College of Medicine, Seoul, ${ }^{12}$ University of Ulsan College of Medicine, Seoul, ${ }^{13}$ Sungkyunkwan University School of Medicine, Seoul, ${ }^{14}$ Korea University College of Medicine, Seoul, Korea

Capsule endoscopy (CE) enables evaluation of the entire mucosal surface of the small bowel (SB), which is one of the most important steps for evaluating obscure gastrointestinal bleeding. Although the diagnostic yield of SB CE depends on many clinical factors, there are no reports on quality indicators. Thus, the Korean Gut Image Study Group (KGISG) publishes an article titled, "Quality Indicators for Small Bowel Capsule Endoscopy" under approval from the Korean Society of Gastrointestinal Endoscopy (KSGE). Herein, we initially identified process quality indicators, while the structural and outcome indicators are reserved until sufficient clinical data are accumulated. We believe that outcomes of SB CE can be improved by trying to meet our proposed quality indicators.

Clin Endosc 2017;50:148-160

Key Words: Capsule endoscopy; Small bowel; Process; Quality; Indicator

\section{INTRODUCTION}

Capsule endoscopy (CE) was introduced in $2000^{1}$ and since then, it has become one of the first-line diagnostic tools for small bowel (SB) disorders. ${ }^{2}$ Currently more than 4000 studies addressing $\mathrm{CE}$ can be found using PubMed. Additionally, applications of CE have been expanded to the evaluation of esophageal and colorectal disorders.

$\mathrm{CE}$ is the best method to evaluate the entire mucosal surface of the SB and it plays a key role in evaluation of obscure

Received: February 9, 2017 Revised: March 14, 2017

Accepted: March 16, 2017

Correspondence: Bo-In Lee

Division of Gastroenterology, Department of Internal Medicine, Seoul St. Mary's Hospital, College of Medicine, The Catholic University of Korea, 222 Banpo-daero, Seocho-gu, Seoul 06591, Korea

Tel: +82-2-2258-2044, Fax: +82-2-2258-2589, E-mail: gidoc4u@gmail.com

(cc) This is an Open Access article distributed under the terms of the Creative Commons Attribution Non-Commercial License (http://creativecommons.org/ licenses/by-nc/3.0) which permits unrestricted non-commercial use, distribution, and reproduction in any medium, provided the original work is properly cited. gastrointestinal bleeding (OGIB). However, the diagnostic yield of SB CE can be affected by many factors, such as indications, bowel preparation, technical errors, view mode and frame rate during interpretation, reviewers' experience, and so on.

Diagnostic procedures with inadequate quality may be related with decreased diagnostic accuracy, procedure-related complications, and unnecessary medical burden. However, there are no publications on quality indicators for SB CE. Thus, the members of Korean Gut Image Study Group (KGISG) decided to establish "Quality Indicators for Small Bowel Capsule Endoscopy" under approval from the Korean Society of Gastrointestinal Endoscopy (KSGE).

Generally, quality indicators refer to specific issues identified for comparison and potential improvement ${ }^{3}$ and they represent a minimally acceptable standard of care. ${ }^{4}$ Quality indicators are classified as structural, process and outcome measures based on the type of assessment. Structural indicators evaluate the health care environment and they are typically scrutinized during accreditation surveys. Process indicators 
Table 1. Grade of Recommendation

\begin{tabular}{|c|c|c|c|}
\hline $\begin{array}{l}\text { Grade of recom- } \\
\text { mendation }\end{array}$ & Clarity of benefit & Methodologic strength supporting evidence & Implications \\
\hline $1 \mathrm{~A}$ & Clear & $\begin{array}{l}\text { Randomized trials without important limita- } \\
\text { tions }\end{array}$ & $\begin{array}{l}\text { Strong recommendation, can be applied } \\
\text { to most clinical settings }\end{array}$ \\
\hline $1 \mathrm{~B}$ & Clear & $\begin{array}{l}\text { Randomized trials with important limitations } \\
\text { (inconsistent results, nonfatal methodologic } \\
\text { flaws) }\end{array}$ & $\begin{array}{l}\text { Strong recommendation, likely to apply to } \\
\text { most practice settings }\end{array}$ \\
\hline $1 \mathrm{C}+$ & Clear & $\begin{array}{l}\text { Overwhelming evidence from observational } \\
\text { studies }\end{array}$ & $\begin{array}{l}\text { Strong recommendation, can apply to } \\
\text { most practice settings in most situations }\end{array}$ \\
\hline $1 \mathrm{C}$ & Clear & Observational studies & $\begin{array}{l}\text { Intermediate-strength recommendation, } \\
\text { may change when stronger evidence is } \\
\text { available }\end{array}$ \\
\hline $2 \mathrm{~A}$ & Unclear & $\begin{array}{l}\text { Randomized trials without important limita- } \\
\text { tions }\end{array}$ & $\begin{array}{l}\text { Intermediate-strength recommendation, } \\
\text { best action may differ depending on } \\
\text { circumstances or patients 'or societal } \\
\text { values }\end{array}$ \\
\hline 2B & Unclear & $\begin{array}{l}\text { Randomized trials with important limitations } \\
\text { (inconsistent results, nonfatal methodologic } \\
\text { flaws) }\end{array}$ & $\begin{array}{l}\text { Weak recommendation, alternative ap- } \\
\text { proaches may be better under some } \\
\text { circumstances }\end{array}$ \\
\hline $2 \mathrm{C}$ & Unclear & Observational studies & $\begin{array}{l}\text { Very weak recommendation, alternative } \\
\text { approaches likely to be better under } \\
\text { some circumstances }\end{array}$ \\
\hline 3 & Unclear & Expert opinion only & $\begin{array}{l}\text { Weak recommendation, likely to change } \\
\text { as data become available }\end{array}$ \\
\hline
\end{tabular}

Adapted from Guyatt et al. $^{5}$

represent care delivery performance and outcome indicators suggest results of care. ${ }^{3}$ Herein we describe process indicators. Structural and outcome indicators have not been covered in this article since there are insufficient clinical studies and evidences regarding the standards of care environments and minimal requirements for care results.

We believe the following quality indicators will be helpful to establish competence of $\mathrm{CE}$ and to improve quality of $\mathrm{CE}$.

\section{METHODS}

Three taskforce teams (preprocedure, intraprocedure, and postprocedure) from KGISG were formed and each team performed systematic literature search and prepared a comprehensive review to identify articles relevant to $\mathrm{CE}$ since the year 2000, using PubMed, MEDLINE, KoreaMed, and Google Scholar. Each team generated indicator candidates. Finally, 16 quality indicators were selected after repetitive discussions. Each candidate indicator, proposed by a team, was reviewed and discussed by other teams in a crossover manner. The grades of recommendation were classified in Table 1 based on levels of evidence. ${ }^{5,6}$ The proposed preprocedural, intraproce- dural, and postprocedural quality indicators common to SB CE are listed in Table 2.

\section{PREPROCEDURAL QUALITY INDICATORS}

\section{Indications}

\section{OGIB}

Capsule endoscopy is recommended as the first-line investigation for patients with obscure gastrointestinal bleeding (grade of recommendation: $1 \mathrm{~A}$ ).

The overall diagnostic yield of CE for OGIB ranges between $30 \%$ and $70 \%$, which is higher than that of other diagnostic modalities (push enteroscopy, double-balloon enteroscopy [DBE], and SB series with sensitivities of $31 \%, 23 \%$, and $5 \%$, respectively). ${ }^{7-9} \mathrm{CE}$ should be performed as soon as possible after the bleeding episode, optimally within 14 days, to maximize the diagnostic yield. ${ }^{7}$ The causative lesions include intestinal angiodysplasia, SB ulcer, blood in the SB without an 
Table 2. Summary of Proposed Quality Indicators Common to Small Bowel Capsule Endoscopy

\begin{tabular}{|c|c|c|}
\hline Quality indicator & $\begin{array}{l}\text { Grade of } \\
\text { recommendation }\end{array}$ & $\begin{array}{l}\text { Measure } \\
\text { type }\end{array}$ \\
\hline \multicolumn{3}{|l|}{ Preprocedural } \\
\hline $\begin{array}{l}\text { Capsule endoscopy is recommended as the first-line investigation for patients with obscure gastro- } \\
\text { intestinal bleeding. }\end{array}$ & $1 \mathrm{~A}$ & Process \\
\hline $\begin{array}{l}\text { Capsule endoscopy is the most sensitive diagnostic modality for detecting mucosal lesions of the } \\
\text { small bowel in patients with suspected or established Crohn's disease. }\end{array}$ & $1 \mathrm{~B}$ & Process \\
\hline Capsule endoscopy is useful for detection of small bowel tumors and polyps. & $2 \mathrm{C}$ & Process \\
\hline $\begin{array}{l}\text { In patients with Crohn's disease, previous abdominal surgery, intestinal ischemia, volvulus, and } \\
\text { history of abdominal radiotherapy, the risk of capsule retention is increased. For risk stratification } \\
\text { and prevention of capsule retention, taking careful clinical history and performing careful physi- } \\
\text { cal examination is essential. }\end{array}$ & 3 & Process \\
\hline $\begin{array}{l}\text { In subjects with Crohn's disease, obstructive symptoms, and suspicious stenosis, small bowel imag- } \\
\text { ing, such as computed tomography enterography or magnetic resonance enterography, should be } \\
\text { methods of choice for patency of small bowel prior to subsequent capsule endoscopy. Additional- } \\
\text { ly, the use of patency capsule to confirm functional patency of the small bowel is recommended. }\end{array}$ & 2C & Process \\
\hline $\begin{array}{l}\text { Intraprocedural and postprocedural patient instructions should be provided in written form before } \\
\text { performing small bowel capsule endoscopy. }\end{array}$ & 3 & Process \\
\hline \multicolumn{3}{|l|}{ Intraprocedural } \\
\hline $\begin{array}{l}\text { Excellent or good preparation ( }>75 \% \text { small bowel visualization) is considered to enhance diagnos- } \\
\text { tic yield of small bowel examination. }\end{array}$ & $1 \mathrm{C}$ & Process \\
\hline $\begin{array}{l}\text { Bowel preparation with purgatives enhances the small bowel visual quality compared with fasting } \\
\text { alone or a clear liquid diet. }\end{array}$ & $1 \mathrm{~B}$ & Process \\
\hline $\begin{array}{l}\text { Photodocumentation of capsule passing through the ileocecal valve or into the colon is necessary } \\
\text { for verification of entire small bowel exploration. }\end{array}$ & $2 \mathrm{C}$ & Process \\
\hline $\begin{array}{l}\text { When capsule endoscopy is performed in patients with high risk of delayed gastric emptying, } \\
\text { identifying capsule's position using plain radiography or real-time viewer after ingestion, or en- } \\
\text { doscopic employment of capsule endoscopy is recommended. }\end{array}$ & $1 \mathrm{~B}$ & Process \\
\hline $\begin{array}{l}\text { Technical errors during capsule endoscopy procedure can decrease quality of the capsule endosco- } \\
\text { py image, although, it seldom occurs. }\end{array}$ & 3 & Process \\
\hline \multicolumn{3}{|l|}{ Postprocedural } \\
\hline $\begin{array}{l}\text { DualView or QuadView may be recommended as the viewing mode to improve reading efficiency } \\
\text { and detection rate of interpreters reading capsule endoscopy. }\end{array}$ & $2 \mathrm{C}$ & Process \\
\hline $\begin{array}{l}\text { During capsule endoscopy reading, } 15 \text { frames per second or less is appropriate for acceptable de- } \\
\text { tection rate. }\end{array}$ & $2 \mathrm{C}$ & Process \\
\hline $\begin{array}{l}\text { Experience with minimum of } 10-20 \text { capsule endoscopy cases is required for trainees to attain cap- } \\
\text { sule endoscopy competency. Because the lesion miss rate during capsule endoscopy is relatively } \\
\text { high, interpretation of findings in capsule endoscopy should be done by experienced and compe- } \\
\text { tent endoscopists. Interpretation performed by a trainee should be reviewed and confirmed by an } \\
\text { expert. }\end{array}$ & $1 \mathrm{C}$ and $2 \mathrm{C}$ & Process \\
\hline $\begin{array}{l}\text { Either conservative or endoscopic treatment can be considered for capsule retention, and the de- } \\
\text { cision depends on patient's symptoms or availability of enteroscopy. Surgical removal of retained } \\
\text { capsule could be reserved for asymptomatic patients. }\end{array}$ & 3 & Process \\
\hline $\begin{array}{l}\text { Procedure reports are required for every capsule endoscopy and should be accurate, concise, and } \\
\text { completed in a timely manner. }\end{array}$ & 3 & Process \\
\hline
\end{tabular}

identified lesion, SB tumors, and SB varices. ${ }^{9,10}$ From about a half to two thirds of patients receiving non-steroidal anti-inflammatory drugs (NSAIDs) have SB lesions such as erosions, petechiae, denudated mucosa, bleeding lesions, ulcers, and etc. $^{11}$ The role of CE is clearer in patients with OGIB after negative results of conventional endoscopy. Iron deficiency ane- 
mia (IDA) is usually determined based on blood loss through the gastrointestinal (GI) tract. Therefore, CE is a good method to identify causative lesions once other common potential bleeding sources located within the reach of conventional endoscopies have been excluded. Additionally, CE is useful in determining the route of device-assisted enteroscopy (DAE).

\section{Crohn's disease}

Capsule endoscopy is the most sensitive diagnostic modality for detecting mucosal lesions of the small bowel in patients with suspected or established Crohn's disease (grade of recommendation: $1 \mathrm{~B})$.

CE plays a role in diagnosing suspected Crohn's disease (CD) when the clinical history is compatible, but not as much as diagnostic ileocolonoscopy. SB endoscopy helps to make differential diagnosis of $\mathrm{CD}$ in suspected $\mathrm{CD}$ patients by identifying $\mathrm{SB}$ involvement proximal to the terminal ileum. It also plays a role in the mucosal severity of the $\mathrm{SB}$ and disease extension in patients with established $\mathrm{CD} .^{7,12-14}$ Meta-analysis showed that the diagnostic yield for SB CD was higher (50\%-70\%) with $\mathrm{CE}$ than with other diagnostic modalities (SB series, 22\%; colonoscopy, $48 \%$; push enteroscopy, $8 \%$; and enteroclysis/ computed tomography enterography [CTE], 31\%). ${ }^{12}$ When stenosis or obstruction is suspected, patency capsule or careful examination using cross-sectional imaging modalities, such as magnetic resonance (MR)/CT, should be considered first.

\section{SB tumor and polyposis syndrome}

Capsule endoscopy is useful for detection of small bowel tumors and polyps (grade of recommendation: $2 \mathrm{C}$ ).

$\mathrm{CE}$ is recommended for patients with OGIB to find $\mathrm{SB}$ tumor. However, DAE is preferred rather than $\mathrm{CE}$ in patients with SB tumor-suspected images. ${ }^{7}$ The most common presentation of SB tumors is OGIB and the most common histopathological type of these tumors is adenocarcinoma, followed by carcinoid tumors, lymphoma, sarcoma, and hamartoma. The most common location is the jejunum ( $40 \%-60 \%)$, followed by the ileum $(25 \%-40 \%)$ and duodenum $(15 \%-25 \%){ }^{10}$ $\mathrm{CE}$ is also useful in detection of SB polyps and surveillance in familial adenomatous polyposis and Peutz-Jeghers syndrome. $^{7,15}$

\section{Celiac disease}

The use of $\mathrm{CE}$ for suspected celiac disease is not routinely recommended. However, it is suggested to use $\mathrm{CE}$ in patients unwilling or unable to undergo conventional endoscopy. ${ }^{7}$

\section{Abdominal pain of unknown origin}

$\mathrm{CE}$ has a low diagnostic yield in patients with abdominal pain (13\%); however, the diagnostic yield of CE can be improved in patients with chronic abdominal pain accompanied with elevated serum inflammatory markers (C-reactive protein, erythrocyte sedimentation rate), weight loss, diarrhea, and so on. ${ }^{16}$

\section{Identifying high-risk patients for capsule retention}

In patients with Crohn's disease, previous abdominal surgery, intestinal ischemia, volvulus, and history of abdominal radiotherapy, the risk of capsule retention is increased. For risk stratification and prevention of capsule retention, taking careful clinical history and performing careful physical examination is essential (grade of recommendation: 3 ).

The capsule is usually excreted with feces within $24-48$ hours of ingestion. Capsule retention (CR) is defined as having a capsule remain in the GI tract for more than 2 weeks or requiring directed surgical or endoscopic intervention. ${ }^{17}$ The known rate of CR is almost $0 \%$ in healthy adults, $13 \%$ in patients with suspected or known $\mathrm{CD}$, and $16 \%$ in patients with symptomatic $\mathrm{SB}$ obstruction. ${ }^{18}$

In cases of $\mathrm{CD}$, up to $66 \%$ of patients have $\mathrm{SB}$ involvement at diagnosis. Twenty-five percent of patients with $\mathrm{CD}$ have had at least one SB stricture. ${ }^{19}$ Data from the hospital-based study with 16-year follow-up period showed that the stricture occurred in $20.1 \%$ of $\mathrm{CD}$ cases. ${ }^{20}$ Other known risk factors associated with CR are NSAIDs enteropathy, previous abdominal surgery, intestinal ischemia, volvulus, and history of abdominal radiotherapy. ${ }^{17}$

In subjects with Crohn's disease, obstructive symptoms, and suspicious stenosis, small bowel imaging, such as computed tomography enterography or magnetic resonance enterography, should be methods of choice for patency of small bowel prior to subsequent capsule endoscopy. Additionally, the use of patency capsule to confirm the functional patency of small bowel is recommended (grade of recommendation: $2 \mathrm{C}$ ).

Since CTE/CT enteroclysis or MR enterography (MRE)/MR enteroclysis could identify strictures and assess the transmural or extraluminal nature of the disease, if subjects have obstructive symptoms or suspicious stenosis, dedicated SB cross-sectional imaging with CTE or MRE generally takes precedence over $\mathrm{CE}$ for evaluation of the $\mathrm{SB} .{ }^{7,21} \mathrm{In} \mathrm{CD}$, the findings of $\mathrm{SB}$ stenosis at CTE or MRE may preclude prior to CE in 27\% 
to $40 \%{ }^{22}$ In the studies using patency capsule instead of CE, MRE has a high negative predictive values $(96.3 \%-100 \%)$ and sensitivity (92.3\%-100\%) for patency CR. ${ }^{23}$

Patency capsule is used before CE to evaluate the patency of the GI tract in patients with stricture or suspected stricture. $^{17}$ According to a study comparing CR rates in high risk patients evaluated with patency capsule and SB cross-sectional imaging, it was more predictable for high risk patients with negative patency capsule to have negative CR than for those who received SB cross-sectional imaging. ${ }^{24} \mathrm{CE}$ following positive patency capsule in patients with $\mathrm{CD}$ was associated with a high risk of CR. However, the risk of CR was not reduced by nonselective use of the patency capsule. ${ }^{25}$ Recently, novel radio frequency identification (RFID) tag-less patency capsule has been introduced to clinical practice to reduce associated risks of the typical patency capsule. The impact of the patency capsule's inner RFID tag in a stricture could cause SB ileus. Use of the tag-less patency capsule can confirm GI tract patency in most of the patients who did not have stenosis during imaging and allowed estimation of the patency for patients who did have stenosis on imaging. ${ }^{26}$

\section{Patient instructions}

Intraprocedural and postprocedural patient instructions should be provided in written form before performing small bowel capsule endoscopy (grade of recommendation: 3 ).

Little is known about whether the diagnostic yield or quality of CE can be influenced by the intraprocedural and postprocedural patient instructions. In general, the manufacturer's guidelines include the acceptable physical activity and dietary intake after swallowing the capsule to ensure successful tests. ${ }^{27,28}$ Early clinical studies related to CE also specifically described the instructions to the patients after capsule ingestion. $^{29,30}$ These instructions mainly include recommendations related to physical activity and acceptable dietary intake while tests are proceeding. In addition, patients should be instructed about when they should return data recorders or suspect the possibility of CR after completion of tests. Details of general instructions are summarized in Supplementary Tables 1 and 2. If needed, individualized instructions could be provided or ordered by the physicians. For example, dietary intake should be restricted for the patient with ongoing overt OGIB who may require urgent or emergent intervention based on the results of $\mathrm{CE}$.

\section{INTRAPROCEDURAL QUALITY INDICATORS}

\section{Bowel preparation}

\section{Quality of adequate bowel preparation}

Excellent or good preparation (>75\% small bowel visualization) is considered to enhance diagnostic yield of small bowel examination (grade of recommendation: 1C).

During CE, several factors, such as bubbles, food material in the SB, and gastric and SB transit time, influence the SB visualization quality (SBVQ), diagnostic yield, and cecal completion rate were analyzed. Therefore, bowel preparation prior to $\mathrm{CE}$ is as important as bowel preparation prior to colonoscopy. Diagnostic yield is defined as a meaningful diagnostic finding of CE. Purgative bowel preparations enhance diagnostic yield of SB examination using CE. ${ }^{31}$

SBVQ was defined as follows: "excellent," if an ideal visualization of the SB mucosa was achieved (>90\%); "good," if $>75 \%$ of the mucosa was in perfect condition; "fair," if only $50 \%-75 \%$ of the mucosa was under perfect conditions; and "poor," if $<50 \%$ of the mucosa could be observed. However, there was no consensus of optimal bowel preparation for CE, as each study with polyethylene glycol (PEG) suggested various definitions for bowel preparation quality. A recent study considered excellent or good preparation $(>75 \%$ SB visualization) as an adequate bowel preparation. ${ }^{32}$

\section{Purgatives of adequate bowel preparation}

Bowel preparation with purgatives enhances the small bowel visual quality compared with fasting alone or a clear liquid diet (grade of recommendation: 1B).

To date, there have been many comparative studies, consensus, and guidelines regarding different types of bowel cleansing agents in bowel preparation for $\mathrm{CE} .^{33}$ Currently, PEGbased regimens are primarily recommended. A 2-L PEG with simethicone is most frequently recommended for CE bowel preparation. Sodium picosulphate-based regimens are recommended as a second option, as their cleansing efficacy is less than that of PEG-based regimens.

According to the guidelines for bowel preparation, which were published by the KGISG in $2013,{ }^{34}$ bowel preparation with PEG compared with fasting alone or clear liquid diet enhances diagnostic yield and SBVQ without effect on cecal completion rate. A 2-L PEG solution for bowel preparation is similar to that of a 4-L PEG solution in diagnostic yield, 
SBVQ, and cecal completion rate of CE. ${ }^{35,36}$ Bowel preparation by fasting or administration of PEG solution, when combined with simethicone, enhances SBVQ, but does not affect cecal completion rate of $\mathrm{CE} .^{37-40}$ Bowel preparation using prokinetics does not enhance SBVQ, diagnostic yield, or cecal completion rate of $\mathrm{CE} .^{34}$

Currently, there has been no consensus regarding optimal timing of bowel preparation before CE. A 2-L PEG-based purge, administered one day prior, is the most commonly used preparation method. In clinical practice, CE exam is followed by colonoscopy in patients with obscure GI bleeding or $\mathrm{CD}$. Therefore, the timing of bowel preparation is frequently dependent on the time of colonoscopic examination. According to a single center study by Black et al., ${ }^{41}$ there was no significant difference of diagnostic yield, and the quality according to timing of SB preparation (14 hours vs. 4 hours prior to the $\mathrm{CE}$ ). The day before bowel preparation showed similar results to the same-day bowel preparation regarding quality, SB transit time, cecal completion rate, and overall diagnostic yield. Considering colonoscopic bowel preparation, shorter time interval between bowel preparation and CE may result in superior visualization. Further study is required for clarification.

\section{Completion rate}

Photodocumentation of capsule passing through the ileocecal valve or into the colon is necessary for verification of entire small bowel exploration (grade of recommendation: $2 \mathrm{C}$ ).

Although CE is a useful tool for evaluating SB disease, it is impossible to visualize the entire $\mathrm{SB}$ in all patients because capsules have not always passed through the ileocecal valve before battery exhaustion due to various reasons. ${ }^{42}$

Complete examination was defined as capsule passing through the ileocecal valve or into the colon on images during its working time. ${ }^{42}$ To increase diagnosis yield, complete examination rate of the entire SB is important.

The incomplete examination rate of the CE based on the 10year data from the Korean CE registry was 33\% (969/2,914). ${ }^{43}$ Multiple logistic regression analysis indicated that completion rates were significantly higher with better bowel preparation and in patients with OGIB. The incomplete rate was significantly higher in elderly patients.

Hospitalization, history of SB surgery, and delayed gastric emptying had been shown to be risk factors for incomplete examination. ${ }^{44}$ Effort to increase complete examination rate is important in order to maximize the diagnostic yield of $\mathrm{CE}$.
When capsule endoscopy is performed in patients with high risk of delayed gastric emptying, identifying capsule's position using plain radiography or real-time viewer after ingestion, or endoscopic employment of capsule endoscopy is recommended (grade of recommendation: 1B).

Gastric retention resulting in capsule failing to enter the duodenum and delayed gastric transit, remaining in the stomach for more than 1-1.5 hours had been known as the major causes for incomplete examination. ${ }^{45}$

The effects of routine use of prokinetics, such as metoclopramide and erythromycin, to enhance gastric transit were inconsistent. ${ }^{46-50}$

Identifying capsule's position using plain radiography or real-time viewer two hours after ingestion is recommended as the effective method to reduce gastric transit time, especially in patients who are more likely to have delayed gastric transit. Particularly, use of external real-time viewer to check the progress of the capsule and prespecified actions, such as additional water swallowing, administration of prokinetics, and endoscopic delivery, significantly improved the completion rate. $^{51-53}$

Although it is invasive, endoscopic delivery of capsule to the duodenum has been used as an optimal method to reduce gastric transit time. Additionally, it can be useful in patients with high risk of delayed gastric emptying, particularly in patients with diabetes, vagotomy, scleroderma, or ongoing hospitalization. ${ }^{53-55}$

\section{Technical errors}

Technical errors during capsule endoscopy procedure can decrease quality of capsule endoscopy images, although, it seldom occurs (grade of recommendation: 3 ).

CE image is of significant importance, because high-quality images provide more information for diagnosis. It is not satisfactory mainly because of factors that reduce CE quality. Images obtained during $\mathrm{CE}$ are exposed to different types of noise; for example, food and gas in the stomach, $\mathrm{SB}$, or colon can reduce image quality. Captured images tend to have technical errors. ${ }^{56}$

Together, results of previous studies allow technical errors to be divided into two types: CE system-related error (communication and transmission error) and patient-related error. CE system-related errors include low resolution, blurred images, and light-related distortions. One of the typical noise types in the capsule image was due to data communication errors. ${ }^{57}$ The CE image quality can be improved by removing noise using a median filter or a smart antenna technique, 
based on the results of these studies. ${ }^{58}$ Patient-related technical errors in CE images can occur in patients with implantable cardiac devices (ICD). The presence of an ICD is one of the relative contraindications for $\mathrm{CE}$. CE interference may arise during the procedure, resulting in alterations of the ICD. ${ }^{59}$ However, few studies show actual interference between the ICD and CE. ${ }^{60}$ Left ventricular assist devices (LVADs) had the tendency to interfere with $\mathrm{CE}$ image capture; therefore, a positioning the CE lead as far away from the LVAD as possible was required. ${ }^{61,62}$ Recently, interference-related problems between CE and LVADs are expected to be solved by replacing the lead sensor with a sensor belt.

Hence, CE image quality plays a critical role in diagnosis. Although there are no published reports of the technical error rate in practice, it is generally considered to be very low. However, because technical errors during the $\mathrm{CE}$ procedure are associated with quality of the $\mathrm{CE}$ image, these need to be reported more carefully. Based on these results, action should be taken to solve or reduce technical errors for better quality CE images.

\section{POSTPROCEDURAL QUALITY INDICATORS}

\section{Interpretation}

\section{View mode}

DualView or QuadView may be recommended as the viewing mode to improve reading efficiency and detection rate of interpreters reading capsule endoscopy (grade of recommendation: $2 \mathrm{C}$ ).

To date, there is no optimal view mode for the best interpretation of CE. However, the appropriate selection image number at the monitor improves reading efficiency and detection rate of interpreters reading $\mathrm{CE}^{63}$ Currently, softwares for $\mathrm{CE}$ reading have several view mode options, including SingleView, DualView, and QuadView, according to the number of images shown in one monitor. ${ }^{64}$ In a survey including 530 members of the American College of Gastroenterology, SingleView, DualView, and QuadView were used by $23.7 \%$, $40.4 \%$, and $54.5 \%$, respectively. ${ }^{65}$ QuadView has a theoretical advantage of longer single frame exposure time compared to SingleView, helping interpreters in detecting more lesions. ${ }^{63,66}$ However, QuadView might have a drawback of making readers rely on their peripheral vision because of simultaneous focusing on several images. ${ }^{66}$

A previous study evaluated the effect on the SB using 10 selected video clips. The playing time from the entry of the capsule into the duodenal bulb to the cecum, without the video being stopped once started, was determined by 11 different combinations of video mode and frame rates in order to evaluate the impact of view mode on reading time and detection rates of lesions. There was no difference in reading time according to view mode at the same frame rate. ${ }^{63}$ However, detection rate was higher in DualView or QuadView than in SingleView: 56\% in SingleView, 83\% in DualView, and $85 \%$ in QuadView at 10 frames per second (f.p.s). There was no significant difference in detection rates between DualView and QuadView regardless of frame rates. Therefore, DualView or QuadView may be recommended for the selection of view mode during $\mathrm{CE}$ reading because of higher detection rates compared to SingleView. Because it has not been determined whether the appropriate view mode for the highest detection rate during CE reading is DualView or QuadView, interpreters can select one of these view modes based on their preference.

\section{Frame rate}

During capsule endoscopy reading, 15 frames per second or less is appropriate for acceptable detection rate (grade of recommendation: $2 \mathrm{C}$ ).

The frame rate means the number of f.p.s that is displayed in a video file by softwares for CE reading. Currently, these softwares provide a various range of frame rates allowing reduction of reading time of thousands of capsule's images. ${ }^{64}$ In a study evaluating the effect of frame rate on reading time and detection rate, slower frame rate increased reading time irrespective of view mode options: compared to 10 f.p.s, the mean playing time of videos shortened by $33 \%, 61 \%$, and $72 \%$ in 15 , 25 , and 40 f.p.s, respectively. ${ }^{63}$ In contrast, when interpreters were asked to manually count angioectasia of each positive image from video clips, detection rates calculated using maximum number of positive images were $75 \%$ in 10 f.p.s, $51 \%$ in 15 f.p.s, and $36 \%$ in 25 f.p.s. There was a significant difference in detection rates according to frame rates. In a study evaluating detection rates among different options based on view mode and frame rates, detection rates were 45\% in SingleView 15 f.p.s, $26 \%$ in SingleView 25 f.p.s, $47 \%$ in QuadView 20 f.p.s, and $43 \%$ in QuadView 30 f.p.s. ${ }^{66}$ These studies suggest that slower frame rates can result in higher detection rates during $\mathrm{CE}$ reading despite the need for longer reading time.

According to a panel consensus of 2002 International Conference of Capsule Endoscopy, the fastest acceptable frame rate of review was 15 f.p.s. ${ }^{67}$ However, the consensus was made by experienced interpreters in $\mathrm{CE}$ reading and the 
frame rate option could have been determined based on their own experience. Actually, a previous study suggested that trainees should begin using the frame rates of 5-10 f.p.s for optimal interpretation. ${ }^{68}$ Based on these results, 15 f.p.s or less (combined with DualView or QuadView) is recommended for appropriate frame rate during $\mathrm{CE}$ reading. Although, the optimal frame rate for acceptable detection rate and reading time is unclear. Further studies are needed to determine the best option for appropriate interpretation based on view mode and frame rate in real practice, considering the experience of interpreters and the optimal lower limit of detection rates.

\section{Reviewer}

Experience with minimum of 10-20 capsule endoscopy cases is required for trainees to attain capsule endoscopy competency (grade of recommendation: 1C).

Because the lesion miss rate during capsule endoscopy is relative high, interpretation of findings in capsule endoscopy should be done by experienced and competent endoscopists. Interpretation performed by a trainee should be reviewed and confirmed by an expert (grade of recommendation: $2 \mathrm{C}$ ).

The utility of CE as a diagnostic tool depends on the accuracy of interpretation. However, lesion miss rate is high possibly because only a small fraction of images shows clinically significant lesions during the reading of capsule images. ${ }^{66}$ The miss rate in CE reading was reported to be $11 \%$ of all SB findings and $18.9 \%$ for single-mass lesions. ${ }^{69}$ The American Society of Gastrointestinal Endoscopy recommended that interpretation of CE should be performed by endoscopists who completed a GI endoscopy training program for the diagnosis and management of small intestinal disease. ${ }^{70}$ However, there is no data addressing issues regarding standardized competency assessment tools and minimum training requirements to ensure competence for CE. Although published guidelines including American Gastroenterological Association, American Society of Gastrointestinal Endoscopy, and KSGE have recommended 25,20 , and 10 cases of $\mathrm{CE}$, respectively as necessary to ensure competence in the interpretation of findings, ${ }^{70-72}$ these recommendations are made based mainly on societal guidelines and expert opinions. Recently, two prospective studies have investigated issues regarding CE learning curves. ${ }^{73,74}$ One single-center prospective study investigated 39 GI fellows based on structured CE training curriculum. ${ }^{73}$ In this study, fellows were grouped according to the number of completed CE interpretations. Mean scores for trainees with fewer than 10, 11 to 20 , and 21 to $35 \mathrm{CE}$ interpretations were $79 \%, 79 \%$, and $85 \%$, respectively. A significant difference was seen between staff and fellow scores with 10 or fewer and 11 to 20 interpretations, respectively $(p<0.001)$. Furthermore, no correlation was observed between CE test scores of trainee and previous endoscopy experience. Another Korean multicenter study also evaluated the number of cases needed for trainees to gain necessary experience for $\mathrm{CE}$ competency. ${ }^{74}$ Most of the mean kappa coefficients were $>0.60$ and $>0.80$ after week 9 and 11 , respectively, which indicates a good agreement of the trainees with the expert after 9 weeks and a very good agreement after 11 weeks. In this study, approximately 10 cases of CE were suggested as a minimum number of $\mathrm{CE}$ required for trainees to attain competency. Taken together, learning curve of $\mathrm{CE}$ interpretation seems to include 10-20 cases of CE for a trainee who has competency in wired endoscopy. During this period, continuous guidance and feedback under proper supervision is warranted.

However, the effect of interpreter's experience on detection of lesions during CE reading has not been fully determined. A recent study including 17 endoscopists with experience from 23 to over 1,000 total CE procedures showed that experience of capsule reading did not significantly affect detection rate: $17 \%$ of the interpreters with the lowest detection rates had reading experience of more than 300 capsules $^{66}$ Although we cannot confirm the effect of experience on detection of the lesion, the inter-observer variability in CE reading is different according to the amount of experience. Several studies showed that the inter-observer variability was higher among non-experienced endoscopists. ${ }^{75-77}$ There has been no study about the additional benefit of interpretation by two experts; however, in a case of a trainee, a review made by an expert is essential for the improvement of interpretation quality.

\section{Complications}

Either conservative or endoscopic treatment can be considered for capsule retention, and the decision depends on patient's symptoms or availability of enteroscopy. Surgical removal of retained capsule could be reserved for asymptomatic patients (grade of recommendation: 3 ).

$\mathrm{CE}$ has been proved to be an effective and safe device in the diagnosis of SB disease with few complications or adverse effects. Retention of capsule, perforation, aspiration, and SB obstruction are reported as complications of CE. Among these, $\mathrm{CR}$ is the most common complication. Retained capsules are usually asymptomatic but may cause partial or complete intestinal SB obstruction in some patients. Several cases where a CR leads to intestinal perforation have been reported. $^{78,79} \mathrm{~A}$ systemic review by Liao et al. stated that among the 164 retained capsules reported in 122 articles, most were 
Table 3. Korean Standard of Capsule Endoscopy Report

\section{Korean Standard of Capsule Endoscopy Report}

1. Institute or Hospital:

2. Patient:

Name:

Age/Sex:

Hospital registration No:

3. Date of study: (d)/(m)/(yr)

4. CE company: Given

IntroMedic (MiroCam)
Olympus
Others

5. CE type: SB/esophagus/colon/stomach

6. Doctor: Ordered by Dr.

Interpreted by Dr.

\section{History}

i) Medical history: none/diabetes mellitus/thyroid disease/hypertension/tuberculosis/renal disease/liver disease/surgery/others:

ii) Recent drug history: none/NSAID/aspirin/steroid/anticoagulant/others:

8. Clinical indications for $\mathrm{CE}$

i) Symptom: abdominal pain/chronic diarrhea/weight loss/melena

ii) Sign: anemia/obscure GI bleeding, overt/obscure GI bleeding, occult/protein-losing enteropathy

iii) Diseases: CD/ulcerative colitis/intestinal tuberculosis/polyposis/intestinal tumor or mass/intestinal ischemia/Celiac sprue/Behçet disease/lymphoma

iv) Others

9. Contraindications for $\mathrm{CE}$

i) Known or suspected GI obstruction, stricture, or fistulas based on the clinical picture or pre-procedure testing (CT or MRE, patency capsule, SB series)

ii) Pediatrics (less than 9 years)

iii) Swallowing disorder

iv) Pregnancy

v) Others

10. Onset of chief complaints: days/months/years ago

11. Studies done before CE

i) None

ii) Choose multiple if performed: EGD/colonoscopy/US/CT/SB series/push enteroscopy/DBE/MRI/angiography/PET/others

iii) Result of pre-CE studies:

negative

suspiciously positive

positive, compatible with $\mathrm{CE}$

positive, independently with $\mathrm{CE}$

12. Characteristics of $\mathrm{CE}$ examination

i) Preparation technique: NPO only/PEG 4 L/PEG 2 L/Fleet/simethicone

ii) Use of prokinetics: none/metoclopramide/erythromycin/mosapride/domperidone/alaxyl/others

iii) Preparation quality: excellent/adequate/inadequate, but exam completed/inadequate, precluding exam

iv) Visualization quality: excellent/inadequate illumination/inadequate preparation

v) Type of equipment malfunction: none/capsule/recorder/others

vi) Endoscopic delivery into duodenum: yes/no

13. Extent of examination

i) Total battery time:

ii) Stomach transit time:

iii) SB transit time:

iv) The furthest identifiable anatomic site: esophagus/stomach/jejunum/ileum/ileocecal valve/right colon/left colon/rectum 
Table 3. Continued

\section{Korean Standard of Capsule Endoscopy Report}

14. Complication: none/CE retention/aspiration

i) If retention occurred,

Site: esophagus/stomach/jejunum/ileum

Cause: gastroparesis/gut stenosis/others/unknown

Outcome: spontaneous pass-out/medical/endoscopic removal/surgical removal/observation still now

Day of elimination: days

ii) If aspiration occurred,

Treatment: none/endoscopic removal/surgical removal

15. Findings

i) Major:

ii) Minor:

iii) Minor:

16. Diagnostic impression

i)

ii) Level of certainty: established of/suspicious of/exclusion of/follow up of in addition,

17. Studies done after CE

None/EGD/colonoscopy/US/SB series/push enteroscopy/DBE or single balloon enteroscopy/CT/MRI/angiography/PET/others

Result of post-CE studies: negative/suspiciously positive/positive, compatible with CE/positive, independently with CE

18. Process after $\mathrm{CE}$ diagnosis

i) Observation with assumption of benign condition/due to patient's refusal to treat

ii) Medication

iii) Endoscopic treatment, EGD/colonoscopy/push enteroscopy/DBE

iv) Surgery

v) Follow up lost

vi) Other

Adapted from Gut Image Study Group ${ }^{85}$

CE, capsule endoscopy; SB, small bowel; NSAID, non-steroidal anti-inflammatory drug; GI, gastrointestinal; CD, Crohn's disease; CT, computed tomography; MRE, magnetic resonance enterography; EGD, esophagogastroduodenoscopy; US, ultrasonography; DBE, double-balloon enteroscopy; MRI, magnetic resonance imaging; PET, positron emission tomography; NPO, nothing per oral; PEG, polyethylene glycol.

surgically removed $(58.7 \%, 108 / 164) .{ }^{42}$ However, according to the full texts of 128 articles, of the 104 retained capsules with clinical symptoms mentioned, 88 were asymptomatic and only 16 were associated with partial or complete intestinal obstruction. ${ }^{42}$ In the case series presented by Höög et al., surgical removal was performed in 27 out of 31 patients with $\mathrm{CR}^{80}$ However, only 9 of 27 patients showed obstructive symptoms. Moreover, there were postoperative deaths in 3 of the 27 cases, 2 due to anastomotic breakdown and 1 due to multi-organ failure. ${ }^{80}$ Considering post-operative complications, decision of surgical removal should be made very carefully. Recent studies showed more favorable results with conservative management, such as treating the underlying disease, in patients with $\mathrm{CD}$, with corticosteroids or anti-tumor necrosis factor (TNF) antibodies, and cessation of NSAIDs in patients with drug-induced enteropathy. Such conservative management induced spontaneous passage of the capsule in $52.4 \%$ of cases. ${ }^{81}$ The longest duration of a case with CR was 6 years and 10 months, which had been asymptomatic. During follow up period, there was also no breakdown of CE. In the case series by Höög et al., one patient who received anti-TNF therapy showed CR due to a $\mathrm{CD} .{ }^{80} \mathrm{He}$ then expelled capsule 2.5 years later. ${ }^{80,82}$ Such cases suggest that conservative or medical management may be a good option in patients with asymptomatic CR. However, a case of disruption of retained $\mathrm{CE}$ after 3 years was also reported. Therefore, a possibility of CE disruption should be informed during "wait and see" strategy period. Another option is endoscopic removal using DBE or single-balloon enteroscopy. Recent study reported treatment strategy for CR by DBE. Their result revealed that $72.7 \%(32 / 44)$ of retained CE could be successfully retrieved by enteroscopy. ${ }^{83}$ Among 12 cases with unsuccessful removal by enteroscopy, spontaneous passage of retained capsule after medication therapy was observed in $11.4 \%(5 / 44)$ of patients, only $6.8 \%(3 / 44)$ needed surgery. Abovementioned results suggested the feasibility of enteroscopic removal of retained capsule and clarified the factors associated with successful removal (jejunal location, antegrade insertion, three or fewer strictures). Abovementioned results also showed successful conservative and endoscopic management of CR. Based on these reports, if there are no symptoms associated with $\mathrm{CR}$, conservative or endoscopic treatment can be considered, and 
surgical removal of retained capsule could be reserved.

\section{CE report}

Procedure reports are required for every capsule endoscopy and should be accurate, concise, and completed in a timely manner (grade of recommendation: 3 ).

Accurate and timely documentation of capsule endoscopic findings and recommendations improve patients care. The task force emphasizes that the CE report should be detailed. The patient's medical history justifying the $\mathrm{CE}$ should be described. The indications are classified into signs and symptoms, and diseases. Standardization of the language and structure of endoscopic reports based on CE structured terminology (CEST) may improve communication between clinicians. ${ }^{84}$ To define the location of lesions more precisely, the temporal location should be defined by time points recorded by CE. The following locations can be detected by specific time-point of landmarks: time of ingestion, time of the first gastric image, time of the first duodenal image, and time of the first colonic image. For practical description, diagnoses are divided into main diagnoses and other diagnoses, which are less important or less associated with the reason for CE. Complications are described as unexpected events that occur during or after the CE. Minimal elements of a CE report are summarized in Table $3 .^{72,84,85}$

\section{CONCLUSIONS}

We expect that the outcome of SB CE can be improved by trying to meet the abovementioned 16 quality indicators. Improvement of the outcomes should be confirmed by following studies. Continuous process of quality improvement should be followed.

\section{Conflicts of Interest}

The authors have no financial conflicts of interest.

\section{Supplementary Materials}

Supplementary materials are available at https://doi.org/10.5946/ ce.2017.030 or via http://e-ce.org/.

\section{REFERENCES}

1. Iddan G, Meron G, Glukhovsky A, Swain P. Wireless capsule endoscopy. Nature 2000;405:417.

2. Song HJ, Shim KN. Current status and future perspectives of capsule endoscopy. Intest Res 2016;14:21-29.

3. Petersen BT. Quality assurance for endoscopists. Best Pract Res Clin Gastroenterol 2011;25:349-360
4. MacLean CH, Saag KG, Solomon DH, Morton SC, Sampsel S, Klippel $\mathrm{JH}$. Measuring quality in arthritis care: methods for developing the arthritis foundation's quality indicator set. Arthritis Rheum 2004;51:193202.

5. Guyatt G, Sinclair J, Cook D, Jaeschke R, Schünemann H, Pauker S. Moving from evidence to action. Grading recommendations-a qualitative approach. In: Guyatt G, Rennie D, eds. Users' guides to the medical literature: a manual for evidence-based clinical practice. Chicago (IL): American Medical Association Press; 2002. p. 599-608.

6. Rex DK, Petrini JL, Baron TH, et al. Quality indicators for colonoscopy. Am J Gastroenterol 2006;101:873-885.

7. Pennazio M, Spada C, Eliakim R, et al. Small-bowel capsule endoscopy and device-assisted enteroscopy for diagnosis and treatment of small-bowel disorders: European society of gastrointestinal endoscopy (ESGE) clinical guideline. Endoscopy 2015;47:352-376.

8. Saperas E, Dot J, Videla S, et al. Capsule endoscopy versus computed tomographic or standard angiography for the diagnosis of obscure gastrointestinal bleeding. Am J Gastroenterol 2007;102:731-737.

9. Shim KN, Moon JS, Chang DK, et al. Guideline for capsule endoscopy: obscure gastrointestinal bleeding. Clin Endosc 2013;46:45-53.

10. Redondo-Cerezo E, Sánchez-Capilla AD, De La Torre-Rubio P, De Teresa J. Wireless capsule endoscopy: perspectives beyond gastrointestinal bleeding. World J Gastroenterol 2014;20:15664-15673.

11. Lim YJ, Yang CH. Non-steroidal anti-inflammatory drug-induced enteropathy. Clin Endosc 2012;45:138-144.

12. Triester SL, Leighton JA, Leontiadis GI, et al. A meta-analysis of the yield of capsule endoscopy compared to other diagnostic modalities in patients with non-stricturing small bowel Crohn's disease. Am J Gastroenterol 2006;101:954-964.

13. Park SK, Ye BD, Kim KO, et al. Guidelines for video capsule endoscopy: emphasis on Crohn's disease. Clin Endosc 2015;48:128-135.

14. Kim M, Jang HJ. The role of small bowel endoscopy in small bowel Crohn's disease: when and how? Intest Res 2016;14:211-217.

15. Syngal S, Brand RE, Church JM, Giardiello FM, Hampel HL, Burt RW. ACG clinical guideline: genetic testing and management of hereditary gastrointestinal cancer syndromes. Am J Gastroenterol 2015;110:223262; quiz 263.

16. Katsinelos P, Fasoulas K, Beltsis A, et al. Diagnostic yield and clinical impact of wireless capsule endoscopy in patients with chronic abdominal pain with or without diarrhea: a Greek multicenter study. Eur J Intern Med 2011;22:e63-e66.

17. Römmele C, Brueckner J, Messmann H, Gölder SK. Clinical experience with the PillCam patency capsule prior to video capsule endoscopy: a real-world experience. Gastroenterol Res Pract 2016;2016:9657053.

18. Mata A, Llach J, Bordas JM. Wireless capsule endoscopy. World J Gastroenterol 2008;14:1969-1971.

19. Chang CW, Wong JM, Tung CC, Shih IL, Wang HY, Wei SC. Intestinal stricture in Crohn's disease. Intest Res 2015;13:19-26.

20. Ye BD, Yang SK, Cho YK, et al. Clinical features and long-term prognosis of Crohn's disease in Korea. Scand J Gastroenterol 2010;45:1178-1185.

21. Ohtsuka K, Takenaka K, Kitazume Y, et al. Magnetic resonance enterography for the evaluation of the deep small intestine in Crohn's disease. Intest Res 2016;14:120-126.

22. Panes J, Bouhnik Y, Reinisch W, et al. Imaging techniques for assessment of inflammatory bowel disease: joint ECCO and ESGAR evidence-based consensus guidelines. J Crohns Colitis 2013;7:556-585.

23. Rozendorn N, Klang E, Lahat A, et al. Prediction of patency capsule retention in known Crohn's disease patients by using magnetic resonance imaging. Gastrointest Endosc 2016;83:182-187.

24. Rondonotti E, Soncini M, Girelli CM, Russo A, de Franchis R. Short article: negative small-bowel cross-sectional imaging does not exclude capsule retention in high-risk patients. Eur J Gastroenterol Hepatol 2016;28:871-875.

25. Nemeth A, Kopylov U, Koulaouzidis A, et al. Use of patency capsule in patients with established Crohn's disease. Endoscopy 2016;48:373-379. 
26. Nakamura M, Hirooka Y, Yamamura T, et al. Clinical usefulness of novel tag-less agile patency capsule prior to capsule endoscopy for patients with suspected small bowel stenosis. Dig Endosc 2015;27:61-66.

27. Medtronic. Patient instructions for PillCam ${ }^{\circledR}$ small bowel capsule endoscopy with the sensor belt [Internet]. Dublin: Medtronic; c2013 [cited 2016 Jun 16]. Available from: http://www.medtronic.com/content/dam/ covidien/library/us/en/product/diagnostic-testing/pillcam-sb-sensor-belt-patient-instructions.pdf

28. IntroMedic. Procedures (MiroCam ${ }^{\circ}$ ) [Internet]. Seoul: IntroMedic; c2007 [cited 2016 Jun 16]. Available from: http://intromedic.com/eng/ sub_patient_procedures2_1_1.html.

29. Costamagna G, Shah SK, Riccioni ME, et al. A prospective trial comparing small bowel radiographs and video capsule endoscopy for suspected small bowel disease. Gastroenterology 2002;123:999-1005.

30. Lewis BS, Swain P. Capsule endoscopy in the evaluation of patients with suspected small intestinal bleeding: results of a pilot study. Gastrointest Endosc 2002;56:349-353.

31. Ladas SD, Triantafyllou K, Spada C, et al. European society of gastrointestinal endoscopy (ESGE): recommendations (2009) on clinical use of video capsule endoscopy to investigate small-bowel, esophageal and colonic diseases. Endoscopy 2010;42:220-227.

32. Rosa BJ, Barbosa M, Magalhães J, Rebelo A, Moreira MJ, Cotter J. Oral purgative and simethicone before small bowel capsule endoscopy. World J Gastrointest Endosc 2013;5:67-73.

33. Song HJ, Moon JS, Shim KN. Optimal bowel preparation for video capsule endoscopy. Gastroenterol Res Pract 2016;2016:6802810.

34. Song HJ, Moon JS, Do JH, et al. Guidelines for bowel preparation before video capsule endoscopy. Clin Endosc 2013;46:147-154

35. Kantianis A, Karagiannis S, Liatsos C, et al. Comparison of two schemes of small bowel preparation for capsule endoscopy with polyethylene glycol: a prospective, randomized single-blind study. Eur J Gastroenterol Hepatol 2009;21:1140-1144.

36. Park SC, Keum B, Seo YS, et al. Effect of bowel preparation with polyethylene glycol on quality of capsule endoscopy. Dig Dis Sci 2011;56:1769-1775.

37. Ge ZZ, Chen HY, Gao YJ, Hu YB, Xiao SD. The role of simeticone in small-bowel preparation for capsule endoscopy. Endoscopy 2006;38:836840 .

38. Albert J, Göbel CM, Lesske J, Lotterer E, Nietsch H, Fleig WE. Simethicone for small bowel preparation for capsule endoscopy: a systematic, single-blinded, controlled study. Gastrointest Endosc 2004;59:487-491.

39. Spada C, Riccioni ME, Familiari P, et al. Polyethylene glycol plus simethicone in small-bowel preparation for capsule endoscopy. Dig Liver Dis 2010;42:365-370.

40. Wei W, Ge ZZ, Lu H, Gao YJ, Hu YB, Xiao SD. Purgative bowel cleansing combined with simethicone improves capsule endoscopy imaging. Am J Gastroenterol 2008;103:77-82.

41. Black KR, Truss W, Joiner CI, Peter S, Weber FH Jr. A single-center randomized controlled trial evaluating timing of preparation for capsule enteroscopy. Clin Endosc 2015;48:234-238.

42. Liao Z, Gao R, Xu C, Li ZS. Indications and detection, completion, and retention rates of small-bowel capsule endoscopy: a systematic review. Gastrointest Endosc 2010;71:280-286.

43. Lim YJ, Lee OY, Jeen YT, et al. Indications for detection, completion, and retention rates of small bowel capsule endoscopy based on the 10year data from the Korean capsule endoscopy registry. Clin Endosc 2015;48:399-404.

44. Westerhof J, Weersma RK, Koornstra JJ. Risk factors for incomplete small-bowel capsule endoscopy. Gastrointest Endosc 2009;69:74-80.

45. Rondonotti E, Herrerias JM, Pennazio M, Caunedo A, Mascarenhas-Saraiva M, de Franchis R. Complications, limitations, and failures of capsule endoscopy: a review of 733 cases. Gastrointest Endosc 2005;62:712-716; quiz 752, 754.

46. Postgate A, Tekkis P, Patterson N, Fitzpatrick A, Bassett P, Fraser C. Are bowel purgatives and prokinetics useful for small-bowel capsule endoscopy? A prospective randomized controlled study. Gastrointest Endosc 2009;69:1120-1128.

47. Almeida N, Figueiredo P, Freire P, et al. The effect of metoclopramide in capsule enteroscopy. Dig Dis Sci 2010;55:153-157.

48. Leung WK, Chan FK, Fung SS, Wong MY, Sung JJ. Effect of oral erythromycin on gastric and small bowel transit time of capsule endoscopy. World J Gastroenterol 2005;11:4865-4868.

49. Caddy GR, Moran L, Chong AK, Miller AM, Taylor AC, Desmond PV. The effect of erythromycin on video capsule endoscopy intestinal-transit time. Gastrointest Endosc 2006;63:262-266.

50. Niv E, Bonger I, Barkay O, et al. Effect of erythromycin on image quality and transit time of capsule endoscopy: a two-center study. World J Gastroenterol 2008;14:2561-2565.

51. Liao Z, Li ZS, Xu C. Reduction of capture rate in the stomach increases the complete examination rate of capsule endoscopy: a prospective randomized controlled trial. Gastrointest Endosc 2009;69(3 Pt 1):418-425.

52. Shiotani A, Honda K, Kawakami M, et al. Use of an external real-time image viewer coupled with prespecified actions enhanced the complete examinations for capsule endoscopy. J Gastroenterol Hepatol 2011;26:1270-1274.

53. Gao YJ, Ge ZZ, Chen HY, et al. Endoscopic capsule placement improves the completion rate of small-bowel capsule endoscopy and increases diagnostic yield. Gastrointest Endosc 2010;72:103-108.

54. Holden JP, Dureja P, Pfau PR, et al. Endoscopic placement of the small-bowel video capsule by using a capsule endoscope delivery device. Gastrointest Endosc 2007;65:842-847.

55. Gibbs WB, Bloomfeld RS. Endoscopic deployment of video capsule endoscopy: does it guarantee a complete examination of the small bowel? Gastrointest Endosc 2012;76:905-909.

56. Moradi M, Falahati A, Shahbahrami A, Zare-Hassanpour R. Improving visual quality in wireless capsule endoscopy images with contrast-limited adaptive histogram equalization. 2015 2nd International Conference on Pattern Recognition and Image Analysis (IPRIA). Rasht, Iran: New York (NY): IEEE Xplore, 2015 Mar 11-12.

57. Lee Y-G, Yoon G. Improvement of blood detection accuracy using image processing techniques suitable for capsule endoscopy. International Journal of Medical, Health, Biomedical, Bioengineering and Pharmaceutical Engineering 2012;6:168-171.

58. Miaou S-G, Jeng S-S, Tsung C-W, Hsiao C-H, Lin T-Y. Transmitting capsule endoscope images with wireless lan and smart antenna systems. Biomed Eng (Singapore) 2006;18:246-254.

59. Dubner S, Dubner Y, Gallino S, et al. Electromagnetic interference with implantable cardiac pacemakers by video capsule. Gastrointest Endosc 2005;61:250-254.

60. Dubner S, Dubner Y, Rubio H, Goldin E. Electromagnetic interference from wireless video-capsule endoscopy on implantable cardioverter-defibrillators. Pacing Clin Electrophysiol 2007;30:472-475.

61. Guyomar Y, Vandeville L, Heuls S, et al. Interference between pacemaker and video capsule endoscopy. Pacing Clin Electrophysiol 2004;27:1329-1330.

62. Van de Bruaene C, De Looze D, Hindryckx P. Small bowel capsule endoscopy: where are we after almost 15 years of use? World J Gastrointest Endosc 2015;7:13-36.

63. Nakamura M, Murino A, O'Rourke A, Fraser C. A critical analysis of the effect of view mode and frame rate on reading time and lesion detection during capsule endoscopy. Dig Dis Sci 2015;60:1743-1747.

64. Kyriakos N, Karagiannis S, Galanis P, et al. Evaluation of four time-saving methods of reading capsule endoscopy videos. Eur J Gastroenterol Hepatol 2012;24:1276-1280.

65. Wolff JH, Uradomo LT, Goldberg EM. Wireless capsule endoscopy practice makes perfect? A survey of capsule endoscopy viewing practices in the United States. Gastrointest Endosc 2009;69:AB201.

66. Zheng Y, Hawkins L, Wolff J, Goloubeva O, Goldberg E. Detection of lesions during capsule endoscopy: physician performance is disappoint- 
ing. Am J Gastroenterol 2012;107:554-560.

67. Lewis BS. How to read wireless capsule endoscopic images: tips of the trade. Gastrointest Endosc Clin N Am 2004;14:11-16.

68. Gunther U, Daum S, Zeitz M, Bojarski C. Capsule endoscopy: comparison of two different reading modes. Int J Colorectal Dis 2012;27:521525.

69. Lewis BS, Eisen GM, Friedman S. A pooled analysis to evaluate results of capsule endoscopy trials. Endoscopy 2005;37:960-965.

70. Faigel DO, Baron TH, Adler DG, et al. ASGE guideline: guidelines for credentialing and granting privileges for capsule endoscopy. Gastrointest Endosc 2005;61:503-505.

71. American Association for the Study of Liver Diseases; American College of Gastroenterology; American Gastroenterological Association (AGA) Institute; American Society for Gastrointestinal Endoscopy. The gastroenterology core curriculum, third edition. Gastroenterology 2007;132:2012-2018.

72. Gut Image Study Group, Lim YJ, Moon JS, et al. Korean society of gastrointestinal endoscopy (KSGE) guidelines for credentialing and granting previleges for capsule endoscopy. Korean J Gastrointest Endosc 2008;37:393-402.

73. Rajan E, Iyer PG, Oxentenko AS, et al. Training in small-bowel capsule endoscopy: assessing and defining competency. Gastrointest Endosc 2013;78:617-622.

74. Korean Gut Image Study Group, Lim YJ, Joo YS, et al. Learning curve of capsule endoscopy. Clin Endosc 2013;46:633-636.

75. Sigmundsson HK, Das A, Isenberg G. Capsule endoscopy (CE): interobserver comparison of interpretation. Gastrointest Endosc 2003;57:AB165.

76. Mergener K, Enns R. Interobserver variability for reading capsule endoscopy examinations. Gastrointest Endosc 2003;57:AB85.
77. Jang BI, Lee SH, Moon JS, et al. Inter-observer agreement on the interpretation of capsule endoscopy findings based on capsule endoscopy structured terminology: a multicenter study by the Korean gut image study group. Scand J Gastroenterol 2010;45:370-374.

78. Gonzalez Carro P, Picazo Yuste J, Fernández Díez S, Pérez Roldán F Roncero García-Escribano O. Intestinal perforation due to retained wireless capsule endoscope. Endoscopy 2005;37:684.

79. Repici A, Barbon V, De Angelis C, et al. Acute small-bowel perforation secondary to capsule endoscopy. Gastrointest Endosc 2008;67:180-183.

80. Höög CM, Bark LÅ, Arkani J, Gorsetman J, Broström O, Sjöqvist $\mathrm{U}$. Capsule retentions and incomplete capsule endoscopy examinations: an analysis of 2300 examinations. Gastroenterol Res Pract 2012;2012:518718.

81. Cheon JH, Kim YS, Lee IS, et al. Can we predict spontaneous capsule passage after retention? A nationwide study to evaluate the incidence and clinical outcomes of capsule retention. Endoscopy 2007;39:10461052.

82. Harrington C, Rodgers C. The longest duration of retention of a video capsule. BMJ Case Rep 2014;2014.

83. Wang Y, Liao Z, Wang P, et al. Treatment strategy for video capsule retention by double-balloon enteroscopy. Gut 2017;66:754-755.

84. Korman LY, Delvaux M, Gay G, et al. Capsule endoscopy structured terminology (CEST): proposal of a standardized and structured terminology for reporting capsule endoscopy procedures. Endoscopy 2005;37:951959.

85. Gut Image Study Group. KSCR, Korean standard of capsule endoscopy report. In: 3rd Symposium of The Korean Gut Image Study Group; 2007 Nov 10; Seoul, Korea. 